\title{
Mechanical Properties of SCC Reinforced with Basalt Fiber and Polypropylene Fiber
}

\author{
Mohammed Ramees C.T. \\ Department of Civil Engineering \\ Mar Athanasius College of Engineering, \\ Kothamangalam, Kerala State-686666
}

\begin{abstract}
The project aims to investigate an experimental study of fiber reinforced self compacting concrete (SCC) containing basalt fibers (BFs) and polypropylene fibers (PF). The mechanical properties of SCC reinforced with basalt fiber and polypropylene fibers were investigated in this study. The influence of basalt fibers (BFs) and polypropylene fibers (PF) with different contents on the compressive strength, flexural strength, splitting tensile strength and stress-strain curve of SCC were investigated. Basalt fibers with an aspect ratio 48 and polypropylene fibers with an aspect ratio 60 . Percentage of fibers considered are 0.5 percent, 1percent and 1.5percent of concrete mix. Ratio of volume of hybridization of fibers includes 1is to1, 1is to3 and 3 is to1(Polypropylene fiber is to Basalt fiber) for the above percentage of fibers.
\end{abstract}

Key Words: self compacting concrete, basalt fiber, polypropylene fiber, mechanical properties

\section{INTRODUCTION \\ 1.1 SELF COMPACTING CONCRETE}

Self-compacting concrete was originally developed in Japan and Europe. It is a concrete that is able to flow and fill every part of the corner of the formwork, even in the presence of dense reinforcement, purely by means of own weight and without the need of for any vibration or other type of compaction. The growth of Self Compacting Concrete by Prof. H.Okamura in 1986 has caused a significant impact on the construction industry by overcoming some of the difficulties related to freshly prepared concrete. The SCC in fresh form reports numerous difficulties related to the skill of workers, density of reinforcement, type and configuration of a structural section, pump-ability, segregation resistance and, mostly compaction. The Self Consolidating Concrete, which is rich in fines content, is shown to be more lasting. First, it started in Japan; numbers of research were listed on the global development of SCC and its micro-social system and strength aspects. Though, the Bureau of Indian Standards (BIS) has not taken out a standard mix method while number of construction systems and researchers carried out a widespread research to find proper mix design trials and self-compact ability testing approaches. The work of Self Compacting Concrete is like to that of conventional concrete, comprising, binder, fine aggregate and coarse aggregates, water, fines and admixtures. To adjust the rheological properties of SCC from conventional concrete which is a remarkable difference, SCC should have more fines content, super plasticizers with viscosity modifying agents to some extent.As compared to conventional concrete the benefits of SCC comprising more strength like non SCC, may be higher due to better compaction, similar tensile strength like non SCC, modulus of elasticity may be slightly lower because of higher paste, slightly higher creep due to paste, shrinkage as normal concrete, better bond strength, fire resistance similar as non SCC, durability better for better surface concrete.Addition of more fines content and high water reducing admixtures make SCC more sensitive with reduced toughness and it designed and designated by concrete society that is why the use of SCC in a considerable way in making of pre-cast products, bridges, wall panels etc. also in some countries.However, various investigations are carried out to explore various characteristics and structural applications of SCC. SCC has established to be effective material, so there is a need to guide on the normalization of self-consolidating characteristics and its behavior to apply on different structural construction, and its usage in all perilous and inaccessible project zones for superior quality control.

SCC can be considered to have a liquid type of behavior in fresh state. Main benefits of using it are (i) reducing the noise caused by vibration; (ii) reducing the cost of placement; (iii) increasing the speed of construction; and (iv) decreasing the number of skilled workers. SCC can be used to overcome the compacting problems of fresh concrete, since it can be placed at every corner of formwork without vibration.

High performance concrete is a definition used for concrete with high strength combined with highly enhanced durability. It is, however, known that high strength leads to an increase in the brittleness of concrete. Thus, introduction of fibers in concrete, as already 2 pointed out by a number of authors, can drastically increase the toughness of high strength concrete.

Micro-fiber functions as a bridge to eliminate the formation of micro-cracks, hence the tensile strength of concrete increases. Since the micro-fibers are short in size, they may be pulled out after macro-cracks are formed. The large fibres have no significant effect on -preventing micro-cracking; however, when the micro-cracks condense into macro-cracks, the large fibres may arrest propagation of macro cracks. The toughness increases substantially with the contribution of the large fibres, but the peak stress remains almost constant.

With the use of different type, shape, and strength of fibres, SCC can be tailored for more possible applications. At this point, however, it is vital to determine the effect of fibres on workability properties of SCC. The characteristic properties of SCC, such as its filling ability and deformability, can be measured by several methods. 
In this study, dispersion and alignment of fibres and their effects on fresh and hardened concrete properties are presented. For fresh concrete properties, four different workability tests were conducted. These are the commonly used slump flow, U-box, V-funnel tests, and the $\mathrm{J}$ ring test. The mechanical properties, including modulus of elasticity, compressive, splitting tensile and flexural strength were determined and also load-displacement curves under bending loadings were obtained to investigate the fracture behavior

\subsubsection{Advantages of Self Compacting Concrete}

- Self compacting concrete offers a rapid rate of concrete placement with faster construction times and ease of flow around congested reinforcement.

- The fluidity and segregation resistance of SCC ensures a high level of homogeneity, minimal concrete voids and uniform concrete strength, providing the potential for a superior level of finish and durability to the structure.

- SCC is often produced with low water-cement ratio providing the potential for high early strength, earlier demoulding and faster use of elements and structures.

- The elimination of vibrating equipment improves the environment on and near construction and precast sites where concrete is being placed,reducing the exposure of workers to noise and vibration. So it is called "the quiet revolution in concrete construction".

- The improved construction practice and performance, combined with the health and safety benefits, make SCC a very attractive solution for both precast concrete and civil engineering construction.

\subsubsection{Disadvantages of Self Compacting Concrete}

- SCC requires higher powder and admixture contents than NVC and so the material cost is higher.

- The increased content of powder and admixture also leads to higher sensitivity of SCC to material variation than that of NVC; thus greater care with quality control is required.

\subsection{FIBER REINFORCED SELF-COMPACTING CONCRETE}

There is an innovative change in the Concrete technology in the recent past with the accessibility of various grades of cements and mineral admixtures. However there is a remarkable development, some complications quiet remained. These problems can be considered as drawbacks for this cementatious material, when it is compared to materials like steel. Concrete, which is a ,quasi-fragile materiale $^{\text {ee }}$, having negligible tensile strength.Several studies have shown that fiber reinforced composites are more efficient than other types of composites. The main purpose of the fiber is to control cracking and to increase the fracture toughness of the brittle matrix through bridging action during both micro and macro cracking of the matrix.
Debonding, sliding and pulling-out of the fibers are the local mechanisms that control the bridging action. In the beginning of macro cracking, bridging action of fibers prevents and controls the opening and growth of cracks. This mechanism increases the demand of energy for the crack to propagate. The linear elastic behavior of the matrix is not affected significantly for low volumetric fiber fractions.At initial stage and the hardened state, Inclusion of fibers improves the properties of this special concrete. Considering it, researchers have focused on studied the strength and durability aspects of fiber reinforced SCC which are:
1. Glass fibers
2. Carbon fibers
3. Basalt fibers
4. Polypropylene fibers etc.

Fiber used in this investigation are of basalt rock fibers polypropylene fibers.

\subsubsection{Basalt Fibers}

Basalt is a natural material that is found in volcanic rocks originated from frozen lava, with a melting temperature comprised between $1500^{\circ}$ and $1700{ }^{\circ} \mathrm{C}$.Its state is strongly influenced by the temperature rate of quenching process that leads to more or less complete crystallization. Perhaps $80 \%$ of basalts are made up by two essential minerals; i.e. plagiocene and pyroxene. Analysing the chemical composition it is possible to observe that $\mathrm{SiO}_{2}$ is the main constituent and $\mathrm{Al}_{2} \mathrm{O}$ is the second one.Basalt fiber, which was developed by Moscow Research Institute of Glass and Plastic in 1953-1954, is a high-tech fiber invented by the former Soviet Union after 30 years of research and development, and its first industrial production furnace that adopted 200 nozzles drain board combination oven bushing process was completed in 1985 at Ukraine fiber laboratory. The base cost of basalt fibers varies in dependence of the quality and type of raw material, production process and characteristics of the final product. As the cost, the chemical and mechanical properties depend from the composition of the raw material. Differences in terms of composition and elements concentration give difference in thermal and chemical stability and more or less good mechanical and physical properties . Overall, the manufacturing process of this kind of fiber is similar to that of glass fiber, but with less energy consumed and no additives, which makes it cheaper than glass or carbon fibers. Using a natural volcanic basalt rock as raw material, basalt fiber is produced by putting raw material into furnace where it is melted at $1450-1500^{\circ} \mathrm{C}$. After this, the molten material is forced through a platinum/rhodium crucible bushings to create fibers.

In addition to the ability to be easily processed using conventional processes and equipments, the basalt fibers do not contain any other additives in a single producing process, which makes additional advantage in cost .Blowing melt technologies are proposed for the production of short and cheap basalt fibers characterized by poor mechanical properties. Continuous basalt fibers 
are produced by spinneret method similarly to glass fibers. Recently, Kim et al. proposed melt-spinning method based on dielectric heating in order to produce fibers on laboratory scale.The increasing application of basalt fiber raised the question whether basalt fiber is harmful to health.Even if asbestos and basalt fibers present similar composition, basalt seems to be safe, because of different morphology and surface properties avoid any carcinogenic or toxicity effects, which are presented by asbestos instead . In particular, Kogan et al. made rats inhale air containing asbestos and basalt fibers for 6 months. In the case of asbestos fibers at a dose of $1.7 \mathrm{~g}$ $\mathrm{kg}^{-1}$ (referred to the body weight of the rat), one third of the animals died, while a dose of $2.7 \mathrm{~g} \mathrm{~kg}^{-1}$ killed all the rats. In the case of the basalt fiber, all the animals survived even when the dose reached the $10 \mathrm{~g} \mathrm{~kg}^{-1}$ concentration. Similar investigations were conducted by McConnell et al. and they also concluded that basalt fibers pose no risk to human beings.

Fig 1 Typical Photograph of Basalt Fiber

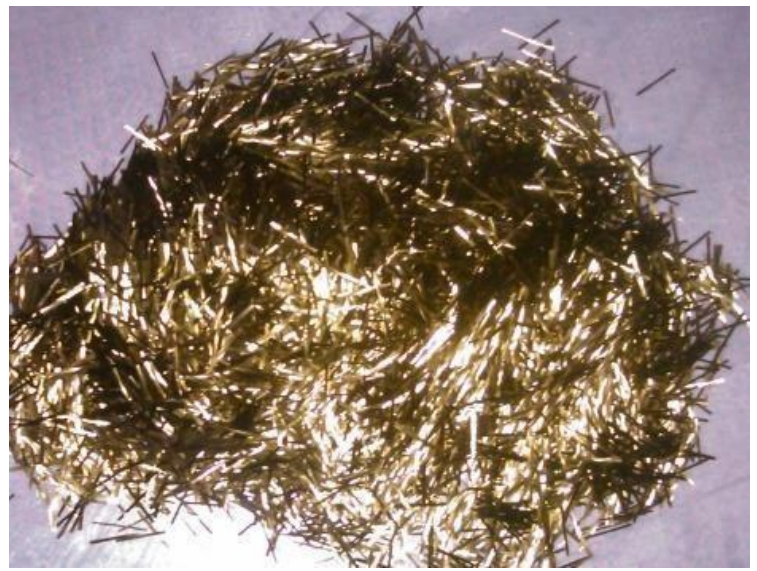

\subsubsection{Polypropylene Fibers}

Polypropylene (PP), also known as polypropene, is a thermoplastic polymer used in a wide variety of applications. It is produced via chain-growth polymerization from the monomer propylene.

Polypropylene belongs to the group of polyolefins and is partially crystalline and non-polar. Its properties are similar to polyethylene, but it is slightly harder and more heat resistant. It is a white, mechanically rugged material and has a high chemical resistance. Polypropylene is the second-

most widely produced commodity plastic (after polyethyle ne) and it is often used in packaging and labeling. In 2013 , the global market for polypropylene was about 55 million tonnes.

Polypropylene is in many aspects similar to polyethylene, especially in solution behaviour and electrical properties. The methyl group improves mechanical properties and thermal resistance, although the chemical resistance decreases. The properties of polypropylene depend on the molecular weight and molecular weight distribution, crystallinity, type and proportion of comonomer (if used) and the isotacticity. In isotactic polypropylene, for example, the methyl groups are oriented on one side of the carbon backbone. This arrangement creates a greater degree of crystallinity and results in a stiffer material that is more resistant to creep than both atactic polypropylene and polyethylene.

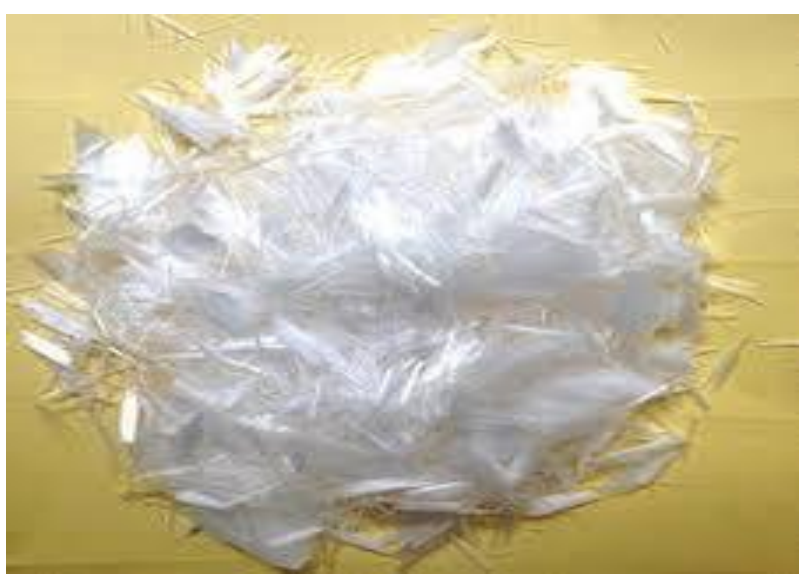

Fig 2 Typical Photograph of Polypropylene Fiber

\section{OBJECTIVE OF THE STUDY}

By conducting the literature review, reveals that to best of my knowledge nobody has attempted to find out the optimum percentage between basalt fibers and polypropylene fibers for effective mechanical properties of SCC. Thereby the objective of my study is,

"To find out the optimum percentage of basalt fibers and polypropylene fibers when set in suitable combinations, that can enhance the mechanical properties of SCC."

\section{SCOPE}

Scope of the study is limited to the following parameters based on available resources and data.

- The study is limited to M30 grade SCC.

- Basalt Rock fibers and Polypropylene fibers of size $12 \mathrm{~mm}$ only are used.

- Fresh properties of SCC checked are flow ability, viscosity and passing ability.

- Hardened properties of SCC checked are compressive strength, split tensile strength, flexural strength.

\section{METHODOLOGY}

Stage 1: In the first stage, all the ingredients for concrete are to be collected and necessary material tests are to be conducted in the laboratory as per relevant Indian standard codes to check their suitability for making self compacting concrete.

Stage 2: Perform the mix design for M30 grade SCC and conduct necessary tests to confirm its effectiveness.

Stage 3: Finding the optimum amount of basalt fiber and polypropylene fiber to be added into the SCC.

Stage 4:Find the rheological properties like passing ability, flow ability, viscosity and mechanical properties like compressive strength, split tensile strength, flexural strength of both control mixes and fiber reinforced SCC.

Stage 5: Comparison of results. 


\section{MATERIALS USED FOR CASTING}

Materials used in this study are,

\subsection{Cement}

$$
\begin{array}{ll}
\text { o } & \text { Cement } \\
\text { o } & \text { Fly ash } \\
\text { o } & \text { Fine Aggregate } \\
\text { o } & \text { Coarse Aggregate } \\
\text { o } & \text { Water } \\
\text { o } & \text { Super Plasticizer } \\
\text { o } & \text { Basalt fiber } \\
\text { o } & \text { Polypropylene fiber }
\end{array}
$$

Ordinary portland cement was used for the present study. The tests were conducted according to Indian Standard recommendations [9]. The physical properties of cement are tabulated in

\begin{tabular}{|c|c|c|}
\hline \multicolumn{3}{|c}{ Table 1 Physical Properties of Cement } \\
\hline 1 & Property & $\begin{array}{c}\text { Obtained } \\
\text { Value }\end{array}$ \\
\hline 2 & $\begin{array}{c}\text { Standard } \\
\text { Consistency(\%) }\end{array}$ & 31.15 \\
\hline 3 & $\begin{array}{c}\text { Initial Setting } \\
\text { Time(minutes) }\end{array}$ & 180 \\
\hline 4 & $\begin{array}{c}\text { Final Setting } \\
\text { Time(minutes) }\end{array}$ & 540 \\
\hline 5 & $\begin{array}{c}\text { Compressive } \\
\text { Strength }(M p a)\end{array}$ & 56 \\
\hline
\end{tabular}

The cement tested comply with the provisions [8, 9, 10], hence it belong to 53 Grade OPC and can be used for making concrete.

\subsection{Coarse Aggregate}

The maximum size of coarse aggregate used in the present study was $12.5 \mathrm{~mm}$. The physical properties of coarse aggregate were tabulated in Table 2 .

Table 2 Physical Properties of Coarse Aggregate
\begin{tabular}{|c|c|c|}
\hline Sl.No & Property & $\begin{array}{c}\text { Obtained } \\
\text { Value }\end{array}$ \\
\hline 1 & Specific Gravity & 2.74 \\
\hline 2 & $\begin{array}{c}\text { Crushing Value } \\
(\%)\end{array}$ & 32.91 \\
\hline 3 & $\begin{array}{c}\text { Water } \\
\text { Absorption }(\%)\end{array}$ & 0.6 \\
\hline 4 & Bulk Density kg/l & 1500 \\
\hline
\end{tabular}

\subsection{Fine Aggregate}

The fine aggregate used for the experimental study was manufactured sand. Fine aggregate under saturated surface dry condition was used for preparing concrete mixes. The physical properties of fine aggregate are given in Table 3.
Table 3 Physical Properties of Fine Aggregate

\begin{tabular}{|c|c|}
\hline Property & Obtained value \\
\hline Specific Gravity & 2.762 \\
\hline $\begin{array}{c}\text { Water Absorption } \\
(\%)\end{array}$ & 1.33 \\
\hline Bulk Density kg/l & 1550 \\
\hline
\end{tabular}

Particle size distribution curve of fine aggregate is depicted in Fig. 3.

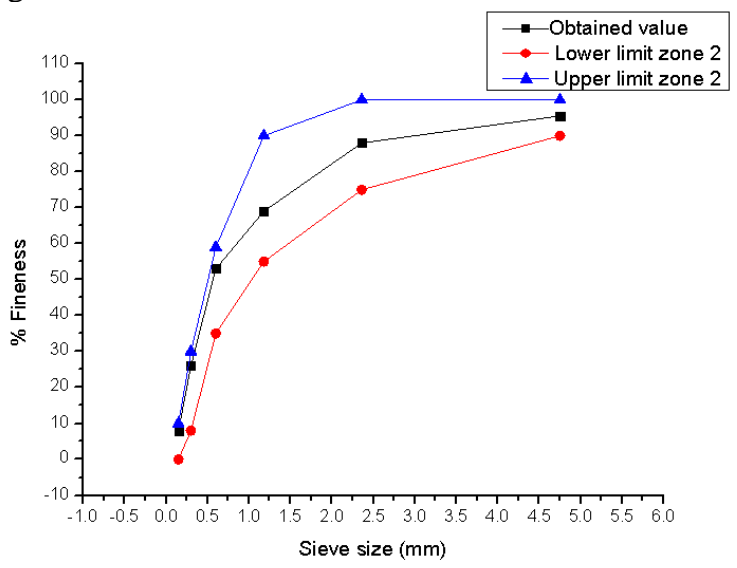

Fig. 3 Particle Size Distribution Curve of Fine Aggregate

\subsection{Fly Ash}

Fly ash is a fine inorganic material with pozzolanic properties, which is added to improve the properties of SCC. Class F fly ash is used for the present study. Specific gravity is 2.58 . Chemical composition of fly ash supplied by manufacturer is tabulated in Table 4 .

Table 4 Chemical Composition of Fly Ash (given by supplier)

\begin{tabular}{|c|c|}
\hline Ingredients & $\begin{array}{c}\text { Percentage (by } \\
\text { manufacturer) }\end{array}$ \\
\hline $\begin{array}{c}\text { Silicon Dioxide + } \\
\text { Aluminum Oxide } \\
\text { + Iron Oxide }\end{array}$ & 11.8 \\
\hline Silicon Dioxide & 58 \\
\hline Reactive Silica & 26 \\
\hline Magnesium Oxide & 1.62 \\
\hline Total Chlorides & 0.0096 \\
\hline
\end{tabular}

\subsection{Superplasticizer}

The superplasticizer used was MasterGlenium SKY 8233. The physical properties of superplasticizer supplied from the manufacture is listed in the Table 5

Table 5. Physical Properties of Superplasticizer (given by supplier)
\begin{tabular}{|c|c|}
\hline Properties & $\begin{array}{c}\text { Value(from } \\
\text { Manufacturer) }\end{array}$ \\
\hline Color & Light brown liquid \\
\hline $\mathrm{pH}$ & $\geq 6$ \\
\hline Relative Density & $1.08 \pm 0.01$ at $25^{\circ} \mathrm{C}$ \\
\hline $\begin{array}{c}\text { Chloride ion } \\
\text { Content }\end{array}$ & $<0.2 \%$ \\
\hline $\begin{array}{c}\text { Magnesium Oxide } \\
(\mathrm{MgO})\end{array}$ & 1.62 \\
\hline
\end{tabular}




\subsection{Water}

Potable water which is available at the laboratory premises was used for mixing of concrete ingredients.

\subsection{Basalt Fibers}

Basalt is a natural material that is found in volcanic rocks originated from frozen lava, with a melting temperature comprised between $1500^{\circ}$ and $1700^{\circ} \mathrm{C}$.Its state is strongly influenced by the temperature rate of quenching process that leads to more or less complete crystallization. Perhaps $80 \%$ of basalts are made up by two essential minerals; i.e. plagiocene and pyroxene. The physical properties of basalt fiber are given in the table given below.

Table 6. Physical Properties of Basalt Fiber

\begin{tabular}{|c|c|}
\hline Properties & Values \\
\hline Length & $12 \mathrm{~mm}$ \\
\hline Diameter & $0.25 \mathrm{~mm}$ \\
\hline Aspect ratio & 48 \\
\hline Density & $2.67 \mathrm{~g} / \mathrm{cm}^{3}$ \\
\hline
\end{tabular}

\subsection{Polypropylene Fiber}

Polypropylene (PP), also known as polypropene, is a thermoplastic polymer used in a wide variety of applications. It is produced via chain-growth polymerization from the monomer propylene.

The physical properties of Polypropylene fiber are given in the table 7 .

\begin{tabular}{|c|c|}
\hline \multicolumn{2}{|c|}{ given below. } \\
\hline Description & Result (by manufacturer) \\
\hline Length & $12 \mathrm{~mm}$ \\
\hline Diameter & $0.20 \mathrm{~mm}$ \\
\hline Aspect ratio & 60 \\
\hline Density & $0.91 \mathrm{~g} / \mathrm{cm}^{3}$ \\
\hline
\end{tabular}

\section{MIX DESIGN}

There is no standard method for SCC mix design and many academic institutions, ready-mixed, precast and contracting companies have developed their own mix proportioning methods. In this study, the mix design procedure was carried out by using modified $\mathrm{Nan} \mathrm{Su}$ method, which satisfied the requirements of EFNARC guidelines. The mix proportion of unit volume of concrete was tabulated in Table 8.

\begin{tabular}{|c|c|} 
Table 8.Quantity of Materials for $1 \mathrm{~m} 3$ Volume of Concrete \\
\hline Materials & Quantity \\
\hline Cement & $375.0 \mathrm{~kg}$ \\
\hline Fine aggregate & $954.8 \mathrm{~kg}$ \\
\hline Coarse aggregate & $756.0 \mathrm{~kg}$ \\
\hline Water & 158.311 \\
\hline Fly ash & $152.69 \mathrm{~kg}$ \\
\hline
\end{tabular}

7.FIBER PROPORTION IN SCC MIX

Table -9: The designation of control mix is shown

\begin{tabular}{|c|c|c|}
\hline \multirow[t]{2}{*}{ Mix ID } & \multicolumn{2}{|c|}{ Volume Fractions of Fibers (\%) } \\
\hline & $\begin{array}{c}\text { POLYPROPYLENE } \\
\text { FIBER }\end{array}$ & $\begin{array}{l}\text { BASALT } \\
\text { FIBER }\end{array}$ \\
\hline F0.0 & 0.000 & 0.000 \\
\hline FB0.5 & 0.000 & 0.500 \\
\hline FB1.0 & 0.000 & 1.000 \\
\hline FB1.5 & 0.000 & 1.500 \\
\hline F0.5P25B75 & 0.125 & 0.375 \\
\hline F0.5P50B50 & 0.250 & 0.250 \\
\hline F0.5P75B25 & 0.375 & 0.125 \\
\hline F1.0P25B75 & 0.250 & 0.750 \\
\hline F1.0P50B50 & 0.500 & 0.500 \\
\hline F1.0P75B25 & 0.750 & 0.250 \\
\hline F1.5P25B75 & 0.375 & 1.125 \\
\hline F1.5P50B50 & 0.750 & 0.750 \\
\hline F1.5P75B25 & 1.125 & 0.375 \\
\hline
\end{tabular}

\section{TESTS ON FRESH CONCRETE}

The following are the tests conducted on fresh concrete[13]

\subsection{Slump-flow and T500 Time for SCC}

The slump-flow and T500 time is a test to assess the flowability and the flow rate of self-compacting concrete in the absence of obstructions. The result is an indication of the filling ability of self-compacting concrete. The T500 time is also a measure of the speed of flow and hence the viscosity of the SCC.

The slump flow test was carried as per the provision given in [13].The fresh concrete is poured into a cone used for slump cone test. When the cone is withdrawn upwards the time from commencing upward movement of the cone to when the concrete has flowed to a diameter of $500 \mathrm{~mm}$ is measured, this is the T500 time. The largest diameter of the flow spread of the concrete and the diameter of the spread at right angles to it are then measured and the mean is the slump-flow[13].

\begin{tabular}{|c|c|c|}
\hline $\begin{array}{l}\text { Slump } \\
\text { Flow } \\
\text { class }\end{array}$ & $\begin{array}{l}\text { Slump Flow } \\
\text { in } \mathrm{mm}\end{array}$ & Applications \\
\hline SF1 & $550-650$ & $\begin{array}{l}\text { - Unreinforced or slightly } \\
\text { reinforced structures } \\
\text { - Casting by a pump injection } \\
\text { system } \\
\text { - Small sections that prevent } \\
\text { long horizontal flow }\end{array}$ \\
\hline SF2 & $660-750$ & 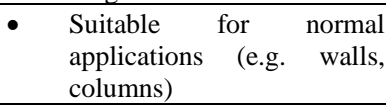 \\
\hline SF3 & $760-850$ & $\begin{array}{l}\text { - Used for small sized } \\
\text { aggregates } \\
\text { Vertical application in } \\
\text { congested structures, } \\
\text { structures with complex } \\
\text { shapes or for filling under } \\
\text { formwork. }\end{array}$ \\
\hline
\end{tabular}

The typical viscosity classes are listed in Table 11: 


\begin{tabular}{|c|c|} 
Table 11 Viscosity Classification \\
\begin{tabular}{|c|c|}
\hline Class & T500 in sec \\
\hline VS1 & $\leq 2$ \\
\hline VS2 & $>2$ \\
\hline
\end{tabular}
\end{tabular}

\subsubsection{V- Funnel Test}

The filling ability (flowability) of the concrete with a maximum aggregate size of $20 \mathrm{~mm}$ can be determined using the $\mathrm{V}$-funnel test. The $\mathrm{V}$-funnel flow time is the period for a defined volume of SCC to pass a narrow opening and gives an indication of the filling ability of SCC provided that blocking and/or segregation do not take place. The test is done as per the provision given in [13]. The typical VFunnel classes and its specifications are listed in Table 9:

Table 12. V-Funnel Classes

\begin{tabular}{|c|c|c|}
\hline Class & $\begin{array}{l}\text { V-funnel } \\
\text { time in sec }\end{array}$ & Specifications \\
\hline VF1 & $\leq 8$ & $\begin{array}{l}\text { - Has good filling } \\
\text { ability even with } \\
\text { congested } \\
\text { reinforcement } \\
\text { - Capable of self- } \\
\text { leveling and has good } \\
\text { surface finish }\end{array}$ \\
\hline VF2 & 9 to 25 & $\begin{array}{l}\text { - Improved segregation } \\
\text { resistance }\end{array}$ \\
\hline
\end{tabular}

\section{$8.3 L-$ Box Test}

The L-box test is used to assess the passing ability of selfcompacting concrete to flow through tight openings including spaces between reinforcing bars and other obstructions without segregation or blocking. There are two variations; the two bar test and the three bar test. The three bar test simulates more congested reinforcement. The test is done as per the provision given in[13]. A measured volume of fresh concrete is allowed to flow horizontally through the gaps between vertical, smooth reinforcing bars and the height of the concrete beyond the reinforcement is measured. The passing ability is calculated from the Eqn. 4.1.

Where, $\mathrm{PA}=$ Passing Ability

$$
\mathrm{PA}=\frac{\mathrm{H}_{2}}{\mathrm{H}_{1}}
$$

$\mathrm{H}_{2}=$ Mean depth of concrete in $(\mathrm{mm})$.

$H_{1}=$ Depth of concrete immediately behind the gate in ( $\mathrm{mm})$.

Fresh properties of mix were tabulated in Table 5.1

The passing ability classes and its applications are listed in Table 4.4:

\begin{tabular}{|c|c|cc|}
\multicolumn{2}{|c|}{ Table 13. Passing Ability Classes } \\
\hline Class & Passing Ability & Applications \\
\hline PA1 & $\begin{array}{c}\geq 0.80 \text { with } 2 \\
\text { rebars }\end{array}$ & $\bullet$ & $\begin{array}{c}\text { Structures with a gap of } 80 \mathrm{~mm} \\
\text { to } 100 \mathrm{~mm}\end{array}$ \\
(Housing, vertical structures)
\end{tabular}

\section{TESTS ON HARDENED CONCRETE}

Testing of hardened concrete plays an important role in controlling and conforming the quality of cement concrete. The main purpose of testing hardened concrete is to conform that the concrete designed has developed the required strength. The tests conducted was cube compressive strength test.

\subsection{Cube Compressive Strength Test}

The cube compressive strength tests was done to obtain the compressive strength behaviour of concrete specimens. The compressive strength at 28 day were found out using compression testing machine as recommended by the Indian Standard Code [15].

\subsection{Split Tensile Strength Test}

The concrete is very weak in tension due to its brittle nature and is not expected to resist the direct tension. The concrete develops cracks when subjected to tensile forces. Thus, it is necessary to determine the tensile strength of concrete to determine the load at which the concrete members may crack. For each mix of cylinders of $(150 \times 300) \mathrm{mm}$ were cast to determine the split tensile strength, as per IS specification after the required curing period of the specimen. Split tensile strength test was conducted at 28 days of curing of concrete cylinder. The test consists of applying a compressive load in which the specimen is placed with its axis horizontal between the compressive platons. The splitting tensile strength is Tsp is calculated using the Eqn 4.2.

$$
\mathrm{Tsp}=\frac{2 \mathrm{P}}{\pi \mathrm{DL}}
$$

Where Tsp $=$ Split tensile strength $\left(\mathrm{N} / \mathrm{mm}^{2}\right)$

$\mathrm{P}=$ Applied load $(N)$

$\mathrm{D}=$ Diameter of the specimen $(\mathrm{mm})$

$\mathrm{L}=$ Length of the specimen $(\mathrm{mm})$

\subsection{Flexural Strength Test}

The flexural strength test was carried out on a prism specimen of dimension $100 \mathrm{~mm} \times 100 \mathrm{~mm} \times 500 \mathrm{~mm}$ as per IS specification [15]. Beams were cast to measure the flexural strength after 28-days. The flexural strength of specimen shall be calculated as Eqn. 4.3;

$$
\text { Flexural Strength }=\frac{\mathrm{PL}}{\mathrm{BD}^{2}}
$$

Where $\mathrm{P}=$ load applied on the prism $(k N)$,

$\mathrm{L}=$ length of the specimen from supports $(\mathrm{mm})$,

$\mathrm{B}=$ measured width of the specimen $(\mathrm{mm})$,

$\mathrm{D}=$ measured depth of the specimen $(\mathrm{mm})$

\subsection{Modulus of Elasticity Test}

The modulus of elasticity of a material is defined by the ratio of applied stress to the corresponding strain within the elastic limit. Physically it indicates a material resistance to being deformed when a stress is applied to it. Modulus of elasticity also indicates the stiffness of a material. The aim of this test is to draw the stress - strain characteristics of the concrete and to find the young's modulus of concrete. The concrete specimen used is a cylinder. The specimen with compressometer was placed in the compression 
testing machine. Corresponding deformation from the load applied in intervals are recorded.

\section{RESULTS AND DISCUSSIONS}

In this chapter the results of various tests conducted on concrete were tabulated and discussed.

\subsection{FRESH PROPERTIES}

The results for the rheological tests were summarized in Table 14

\begin{tabular}{|c|c|c|c|c|c|c|c|c|}
\hline Mi & T5 & Cla & Slum & Cla & L - & Cla & V- & Cla \\
X & 00 & ss & p- & ss & box & ss & funn & ss \\
ID & $(\mathrm{s})$ & of & Flow & of & Tes & of & el & of \\
& & SC & $(\mathrm{mm}$ & SC & t & SC & Test & SC \\
& & C & ) & C & $(\mathrm{m}$ & $\mathrm{C}$ & $(\mathrm{s})$ & $\mathrm{C}$ \\
& & {$[13$} & & {$[13$} & $\mathrm{m})$ & {$[13$} & & {$[13$} \\
& & ] & & ] & & ] & & ] \\
\hline F0. & 9 & VS & 750 & SF2 & 0.9 & PA & 12.0 & VF \\
0 & & 2 & & & 9 & 2 & & 2 \\
\hline
\end{tabular}

All mixes were able to flow and fill into the framework, which was reaffirmed in slump flow tests. The passing ability was investigated in the L-box test.

\subsection{HARDENED PROPERTY}

The respective result for the hardened self compacting concrete

Table 15. Hardened Properties of SCC

\begin{tabular}{|c|c|}
\hline Mix ID & Compressive Strength (MPa) (7days) \\
\hline F0.0 & 37 \\
\hline
\end{tabular}

\section{CONCLUSIONS}

Based on the experiments investigations conducted and interpretation of results, the following major conclusions can be drawn;

- The mix id F0.0 gives T500 in 9 seconds so it is class of VS2

- The mix id F0.0 gives slump flow $750 \mathrm{~mm}$ so it is class of SF2 and suitable for normal applications

- Passing ability 0.99 so it is class of PA2 and The mix F0.0 is suitable for civil engineering structures

- $\quad \mathrm{V}$ funnel test gives 12 seconds so it is class of VF2 and it has improved segregation resistance

- 7 days compressive strength of F0.0 mix is $37 \mathrm{Mpa}$ and it is satisfactory

\section{REFERENCES}

[1] Zeynep Algin and Mustafa Ozen, 'The properties of chopped basalt fibre reinforced self-compacting concrete', Journal of Constructional and Building Materials, Vol. 186, 2018,pp. 678-685.

[2] K.Senthilkumar, N.Rajini, M.Chandrasekar, M.Jawaid, SuchartSiengchin, Othman Y.Alotman, 'Mechanical properties evaluation of sisal fibre reinforced polymer composites',Construction and Building Materials,Vol. 174, 2018, pp. 713-729.

[3] Dehong Wang, Yanzhong Ju, Hao Shen, Libin Xu, "Mechanical properties of high performance concrete reinforced with basalt fiber and polypropylene fiber, Structural Engineering" Newslett. Vol.7, 2002, pp. 25- 32.

[4] Piotr Smarzewski, "influence of basalt-polypropylene fibres on fracture properties of high performance concrete"
[5] Malgorzata Pająk, and Tomasz Ponikiewski, 'Experimental Investigation on Hybrid Steel Fibers Reinforced Selfcompacting Concrete under Flexure',Procedia Engineering ,Vol. 193,2017, pp. 218- 225.

[6] P.Loganathan and G.S. Thirumaganam, 'Experimenta study on mechanical properties and durability properties of hybrid fiber reinforced concrete using steel and banana fibers', Journal of Structural Engineering,Vol. 44, 2018, pp. 147- 158 .

[7] Robert F. Blanks and Henry L.Kennedy, 'The Technology of Cement and Concrete', Concrete materials,Vol.1, John Wiley \& Sons, pp. 52.

[8] IS:4031 part 4: (1988)- 'Method of Physical Tests for Hydraulic Cement', Bureau of Indian Standards, New Delhi, India.

[9] IS:383(1970)- 'Specification for coarse and fine aggregate from natural sources for concrete', Bureau of Indian Standards, New Delhi, India.

[10] IS:2386 Part 1-(1963), 'Methods of Test for Aggregates for Concrete - Part 1 Particle Size and Shape', Bureau of Indian Standards, New Delhi, India.

[11] IS:12296 (2013)- 'Ordinary Portland Cement, 53 grade' Bureau of Indian Standards,New Delhi, India.

[12] Vilas V. KArjinni, and Shrihail B. Anandhini (2009), 'Mixture Proportion Procedure for SCC', The Indian Concrete Journal,Vol. 83, 2009, pp. 34-40.

[13] EFNARC (2005) The European Guidelines for SelfCompacting Concrete Specification, Production and Use.

[14] A.M. Neville, Properties of Concrete, Addison Wesley Longman Ltd.,page 126.

[15] IS:516-1959, 'Methods of Tests for Strength of India. 